\title{
Produção de tomate hidropônico utilizando rejeito da dessalinização na solução nutritiva aplicados em diferentes épocas
}

\author{
Christiano R. Cosme ${ }^{1}$, Nildo da S. Dias ${ }^{1}$, André M. de O liveira ${ }^{1}$, \\ Ermelinda M. M. O liveira ${ }^{2} \& 0$ svaldo N. de Sousa N eto ${ }^{1}$
}

\begin{abstract}
RESU MO
0 objetivo desta pesquisa foi avaliar a resposta do tomateiro (Lycopersicon esculentum) em cultivo hidropônico, adicionando água de rejeito da dessalinização na composição da solução nutritiva, obtendo-se três níveis de salinidade da solução nutritiva: 7,1; 8,7 e 10,1 dS m¹, além da testemunha (sem adição do rejeito: $2,1 \mathrm{dS} \mathrm{m}^{-1}$ ), iniciando-se sua aplicação em diferentes estágios de desenvolvimento da cultura: 7; 32 e 58 dias após o transplantio (DAT). 0 delineamento foi inteiramente casualizado, com 9 tratamentos e três repetições cada, arranjados em um esquema fatorial 3x3 (níveis de salinidade $x$ época de início da aplicação da salinidade), mais a testemunha. A salinidade da solução nutritiva produzida pelo rejeito salino reduziu, de forma significativa, a matéria fresca da parte aérea, matéria seca da parte aérea e a produção dos frutos da cultura do tomate. A época de início da aplicação do rejeito à solução nutritiva, reduziu apenas a matéria seca da parte aérea e a produção de frutos do tomateiro, quando aplicado a partir dos 7 DAT, enquanto a interação desses fatores não produziu efeito significativo para as variáveis estudadas.
\end{abstract}

Palavras-chave: Lycopersicon esculentum, rejeito salino, salinidade

\section{Hydroponic tomato production using reject of desalination in the nutrient solution applied at different stages}

\begin{abstract}
The objective of this study was to evaluate the response of tomato (Lycopersicon esculentum) in a hydroponic system, adding water from desalination in the composition of the nutrient solution, resulting in three levels of salinity of nutrient solution: 7,1; 8,7 and $10,1 \mathrm{dS} \mathrm{m}^{-1}$, and the control (without addition

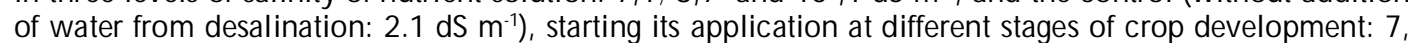
32 and 58 days after transplanting (DAT). The design was completely randomized with 9 treatments and 3 replications, arranged in a $3 \times 3$ factorial design (levels of salinity $x$ starting time of the application of salinity), and control. The salinity of the nutrient solution produced by the saline water, significantly reduced the fresh weight of shoot, dry weight of shoots, and fruit production of tomato. The stage of the application of water in the nutrient solution only reduced the dry matter of shoot and fruit yield of tomato, when applied from 7 DAT, while the interaction of these factors did not produce significant effects for the variables.
\end{abstract}

Key words: Lycopersicon esculentum, saline waste, salinity

Trabalho submetido e selecionado no primeiro Simpósio Brasileiro de Salinidade realizado de 12-15/10/2010 em Fortaleza, Ceará, Brasil ${ }^{1}$ DCA/U FERSA, BR 110 do km 47, Costa e Silva, CEP 59625-900, M ossoró, RN. Fone: (84) 3312-1799. E-mail: christianoreboucas@hotmail.com; nildo@ufersa.edu.br; minidote9@hotmail.com; neto2006osvaldo@yahoo.com.br

2 Unidade Acadêmica Especializada em Ciências Agrárias/UFRN, RN 160, Km 3, CEP 59289-000, Distrito de Jundiaí, Macaíba, RN. Fone: (84) 22185490. Email: ermelindamota@yahoo.com.br 


\section{INTRODUÇÃO}

O tomateiro (Lycopersicon esculentum), é uma das espécies hortícolas de maior importância no mundo, sendo utilizada tanto para consumo fresco como para a indústria. No Brasil, o tomateiro constitui uma das hortaliças de fruto mais importantes comercialmente, com uma produção anual de 3,2 milhões de toneladas, numa área plantada em torno de 63.000 ha e produtividade média de $54 \mathrm{Mg} \mathrm{ha}^{-1}$ (Agrianual, 2008).

A região semiárida do Nordeste, especialmente o Polígono das Secas, apresenta um regime pluviométrico marcado por extrema irregularidade de chuvas, no tempo e no espaço, aliadas às elevadas taxas de evapotranspiração e ao predomínio de rochas impermeáveis (embasamento cristalino), favorecem a escassez de águas superficiais (Costa et al., 2006) e desfavorecem a implantação de sistemas de produção agrícola convencionais em sequeiro; neste cenário, a escassez de água constitui um forte entrave ao desenvolvimento socioeconômico e, até mesmo, à subsistência da população, caso em que as águas subterrâneas são apontadas como alternativa viável para garantir o acesso à água, a partir de investimentos públicos na perfuração de poços tubulares.

Entretanto, essas fontes hídricas apresentam na maioria dos casos restrições de uso para dessedentamento humano (Ayers $\&$ Westcot, 1999), por apresentarem, em sua maioria, problemas de salinidade.

De acordo com os resultados dos estudos da MME (2005), verifica-se, onde foram coletadas e analisadas amostras de 528 poços tubulares da região de Mossoró, $\mathrm{RN}$, a predominância de águas salobras e salinas, com 93,90\% dos poços amostrados. Diante disto, a tecnologia da dessalinização da osmose reversa tem sido amplamente utilizada para o tratamento dessas águas salobras (Porto et al., 2004). Porém, segundo Soares et al. (2006), a dessalinização gera, além da água potável, um rejeito altamente salino e de poder poluente elevado. Considerando a alta frequência de águas salobras nos recursos subterrâneos de regiões semiáridas, como a brasileira, seu uso poderia causar grande impacto ambiental (salinização), caso o sistema de cultivo fosse o convencional baseado no solo (Soares et al., 2007).

Desta forma, o aproveitamento do rejeito salino gerado pela dessalinização por osmose reversa para o preparo de soluções nutritivas para cultivos hidropônicos de hortaliças, surge como uma forma interessante para destinar este resíduo, como mostram os resultados de pesquisas de diversos autores (Soares et al., 2007; Dias et al., 2010; Santos et al., 2010a; 2010b). Desta forma, os cultivos hidropônicos podem constituir uma vantagem quando se utiliza água salobra pois, neste sistema, inexiste o potencial mátrico devido ao estado de saturação ao qual plantas estão submetidas, fato que possibilita o aumento da resposta das culturas à salinidade (Soares et al., 2007).

O tomateiro é uma cultura classificada como moderadamente sensível aos sais, segundo Ayers \& Westcot (1999) e, de acordo com Maas (1990), a tolerância aos sais por determinada cultura, é afetada por diversos fatores, como o estágio de desenvolvimento no momento da exposição aos sais, duração da exposição aos sais, condições ambientais, propriedades físicas e químicas do solo e do tipo e intensidade do manejo. Teixeira (1996), destaca que em quase todos os estados brasileiros se cultivam hortaliças em hidroponia, cujas culturas principais são alface, rúcula, pimentão, morango e tomate.

Ante o exposto acima este trabalho foi desenvolvido com o objetivo de avaliar a produtividade e o comportamento do tomateiro em sistema hidropônico com substrato, utilizandose água de rejeito da dessalinização por osmose reversa na composição da solução nutritiva, em diferentes épocas de início da aplicação dos níveis de salinidade.

\section{Material e MÉTOdos}

O experimento foi conduzido de 19 de julho a 05 de novembro de 2009, em casa de vegetação, no Departamento de Ciências Ambientais e Tecnológicas da Universidade Federal Rural do Semiárido - UFERSA, Mossoró, RN, Brasil, localizada nas coordenadas geográficas de $5^{\circ} 11^{\prime}$ de latitude sul e $37^{\circ} 20^{\prime}$ de longitude oeste, com altitude média de $18 \mathrm{~m}$. O clima da região, na classificação de Köppen, é do tipo BSwh' (quente e seco), com precipitação pluviométrica bastante irregular, média anual de $673,9 \mathrm{~mm}$; temperatura de $27^{\circ} \mathrm{C}$ e umidade relativa do ar média de 68,9\% (Carmo Filho \& Oliveira, 1995).

As sementes de tomate (grupo Santa Cruz, cv. Kada gigante), foram semeadas em bandejas de poliestireno expandido em 128 células preenchidas com substrato de fibra de coco, no dia 19 de julho. O transplantio para as unidades experimentais foi realizado no dia 30 de julho. As unidades experimentais eram constituídas de vasos plásticos preenchidos com o substrato fibra de coco (Golden Mix ${ }^{\circledR}$ ), posicionados em 6 fileiras espaçadas $1,00 \mathrm{~m}$ entre fileiras e $0,50 \mathrm{~m}$ entre vasos. A condução da cultura foi feita em espaldeiras verticais de $2 \mathrm{~m}$ de altura e com auxílio de fita de ráfia, eliminando-se o excesso de brotações laterais, por meio de podas manuais. À medida em que as plantas se desenvolviam, eliminavam-se algumas hastes e folhas velhas da parte basal, para melhorar a luminosidade e ventilação.

O experimento foi conduzido em delineamento inteiramente casualizado, aplicando-se três níveis de salinidade da solução nutritiva $\left(\mathrm{S}_{1}=7,1 ; \mathrm{S}_{2}=8,7\right.$ e $\left._{3}=10,1 \mathrm{dS} \mathrm{m}^{-1}\right)$ iniciando-se em três diferentes épocas de desenvolvimento da cultura (EA), ou seja: 7; 32 e 58 dias após o transplantio (DAT), formando 9 tratamentos, arranjados em um esquema fatorial 3x3 (níveis de salinidade $x$ época de início da aplicação da salinidade), mais a testemunha, correspondentes à sequência: $T_{1}=S_{1}, S_{1}$ e $S_{1}$; $\mathrm{T}_{2}=\mathrm{S}_{0}, \mathrm{~S}_{1}$ e $\mathrm{S}_{1} ; \mathrm{T}_{3}=\mathrm{S}_{0}, \mathrm{~S}_{0}$ e $\mathrm{S}_{1} ; \mathrm{T}_{4}=\mathrm{S}_{2}, \mathrm{~S}_{2}$ e $\mathrm{S}_{2} ; \mathrm{T}_{5}=\mathrm{S}_{0}, \mathrm{~S}_{2}$ e $\mathrm{S}_{2}$; $\mathrm{T}_{6}=\mathrm{S}_{0}, \mathrm{~S}_{0}$ e $\mathrm{S}_{2} ; \mathrm{T}_{7}=\mathrm{S}_{3}, \mathrm{~S}_{3}$ e $\mathrm{S}_{3} ; \mathrm{T}_{8}=\mathrm{S}_{0}, \mathrm{~S}_{3}$ e $\mathrm{S}_{3}$ e $\mathrm{T}_{9}=\mathrm{S}_{0}, \mathrm{~S}_{0}$ e $\mathrm{S}_{3}$, mais o tratamento testemunha, Test. $=\mathrm{S}_{0}, \mathrm{~S}_{0}$ e $\mathrm{S}_{0}\left(\mathrm{~S}_{0}=2,1 \mathrm{dS} \mathrm{m}^{-1}\right)$, sendo que os $1^{\circ}, 2^{\circ}$ e $3^{\circ}$ termos desses tratamentos correspondem às épocas de início da aplicação da solução salina.

Os três níveis de salinidade da solução nutritiva foram obtidos pela mistura de água de rejeito da dessalinização por osmose reversa (AR), coletada de uma unidade de tratamento de água salobra em uma comunidade rural localizada na zona rural de Mossoró, RN, com água de abastecimento (AA) proveniente do campus da UFERSA $\left(\mathrm{CE}_{\mathrm{a}}=0,52 \mathrm{dS} \mathrm{m} \mathrm{m}^{-1}\right)$, nas seguintes proporções: $\mathrm{S}_{1}=50 \% \mathrm{AA}+50 \% \mathrm{AR} ; \mathrm{S}_{2}=25 \% \mathrm{AA}+$

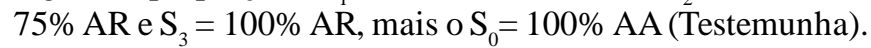


Após a mistura das águas foram adicionados os fertilizantes da solução nutritiva básica, a composição da solução nutritiva foi de 8,$5 ; 2,2 ; 2,0 ; 5,8 ; 3,7 ; 2,2$ e 2,5, em mmol $\mathrm{L}^{-1}$, de $\mathrm{NO}_{3}^{-}$, $\mathrm{NH} 4^{+}, \mathrm{P}, \mathrm{K}, \mathrm{Ca}, \mathrm{Mg}$ e S, respectivamente, e de $60 ; 50 ; 13 ; 1,7 ; 0,5$ e 0,4, em mmol $\mathrm{L}^{-1}$, de Fe, B, Mn, Zn, Cu e Mo, respectivamente, conforme a recomendação para tomateiro, citada por Furlani et al. (1999). Como fontes dos nutrientes foram utilizados os seguintes fertilizantes: nitrato de cálcio, nitrato de potássio, fosfato monoamônio, cloreto de potássio, sulfato de potássio, sulfato de magnésio, sulfato ferroso, sulfato de cobre, sulfato de zinco, sulfato de manganês, ácido bórico e molibdato de amônio.

A solução nutritiva foi fornecida diariamente, de forma manual, com a utilização de uma proveta, sendo o volume de solução suficiente para preencher o substrato na capacidade máxima de retenção, calculado a partir de tensiômetros instalados a $20 \mathrm{~cm}$ de profundidade e da curva característica de retenção de água da fibra de coco nos vasos, construída previamente. Para cada nível de salinidade a solução nutritiva foi armazenada em tanque independente de $250 \mathrm{~L}$, sendo a solução nutritiva renovada a cada 15 dias. A CE da solução e o $\mathrm{pH}$ foram medidos a cada 2 dias durante a irrigação. $\mathrm{O}$ pH médio da solução nutritiva ao longo do ciclo do experimento foi mantido entre a faixa de 6,0 a 6,5, em todos os tratamentos.

As variáveis analisadas foram: produção de frutos (PF), obtida através da soma dos pesos dos frutos das duas colheitas realizadas ( 18 de outubro e 05 de novembro), o diâmetro do colo da planta (DC), e a matéria fresca (MFPA) e seca (MSPA) da parte aérea da planta, obtidas ao término do experimento, quando foi possível retirar toda a parte vegetativa de cada planta, excluindo o sistema radicular, para ser pesada em balança eletrônica, acondicionando o material em embalagens de papel e posta à secagem em estufa a $70^{\circ} \mathrm{C}$, até produção constante.

As análises estatísticas foram realizadas utilizando-se o programa Assistat ${ }^{\circledast}$. Os efeitos dos diferentes níveis de salinidade, época de início da aplicação e sua interação sobre as variáveis estudadas, foram avaliados por métodos convencionais da análise de variância (teste F), aplicando-se os testes Tukey e Dunnet, para comparação de médias para os casos em que ocorreu efeito significativo.

\section{RESULTADOS E DISCUSSÃO}

De acordo com a análise de variância das variáveis estudadas (Tabela 1), verificou-se que os níveis de salinidade (S) da solução nutritiva influenciaram significativamente os resultados das variáveis analisadas: matéria fresca da parte aérea (MFPA), matéria seca da parte aérea (MSPA) e produção de frutos (PF) $(\mathrm{P}<0,01)$ e DC $(\mathrm{P}<0,05)$.

Com relação à época de início da aplicação da salinidade às plantas (EA), só apresentou significância para as variáveis MSPA $(\mathrm{P}<0,05)$ e PF $(\mathrm{P}<0,01)$. A interação entre S e EA não proporcionou efeito significativo para nenhuma das variáveis, ressaltando-se que no caso do tomateiro o efeito do aumento da salinidade da solução nutritiva independe da época em que as plantas são expostas aos sais. Na comparação entre a testemunha e os demais tratamentos houve diferenças para
Tabela 1. Resumo da análise de variância para matéria fresca (M FPA) e seca (M SPA) da parte aérea, diâmetro do colo (DC) e produção de frutos (PF) do tomateiro submetido a três níveis de salinidade da água de irrigação e três épocas de início da aplicação da salinidade (EA)

\begin{tabular}{|c|c|c|c|c|c|}
\hline \multirow{2}{*}{ FV } & \multirow{2}{*}{ GL } & \multicolumn{4}{|c|}{ Estatística F } \\
\hline & & MFPA & MSPA & PF & $D C$ \\
\hline Salinidade (S) & 2 & $20,13^{* *}$ & $15,82^{*} *$ & $22,00 * *$ & $3,87 *$ \\
\hline $\begin{array}{c}\text { Epoca de início } \\
\text { da aplicacão (EA) }\end{array}$ & 2 & $1,91^{\mathrm{NS}}$ & $3,49 *$ & $21,79 * *$ & $0,32^{\mathrm{NS}}$ \\
\hline$S \times E A$ & 4 & $0,55^{\mathrm{NS}}$ & $1,24^{\mathrm{NS}}$ & $1,10^{\mathrm{NS}}$ & $0,72^{\mathrm{NS}}$ \\
\hline $\begin{array}{l}\text { Fatorial VS } \\
\text { Testemunha }\end{array}$ & 1 & $24,30 * *$ & $12,88^{* *}$ & $168,73^{* *}$ & $1,66^{\mathrm{NS}}$ \\
\hline Tratamentos & 9 & $7,84 * *$ & $6,27 * *$ & $28,97 * *$ & $1,44^{\mathrm{NS}}$ \\
\hline Erro & 20 & - & - & - & - \\
\hline CV (\%) & - & 6,52 & 9,14 & 12,08 & 5,29 \\
\hline
\end{tabular}

(NS) não significativos a 0,05, $\left(^{*}\right)$ significativo a 0,05 e $\left(^{* *}\right)$ significativo a 0,01 de probabilidade, pelo teste $\mathrm{F}$

MFPA, MSPA e PF ( $<<0,01)$, não se observando o mesmo para diâmetro do colo, comportamento este observado na comparação entre as médias do fatorial $\left(7,1 ; 8,7\right.$ e 10,1 dS m $\left.{ }^{-1}\right)$ com a testemunha $\left(2,1 \mathrm{dS} \mathrm{m}^{-1}\right)$, com exceção do DC (Tabela 2).

Tabela 2. Efeito da salinidade da solução nutritiva sobre a matéria fresca (MFPA) e seca (MSPA) da parte aérea, produção de frutos (PF) e diâmetro do colo (DC). Valores médios calculados entre diferentes época de aplicação da salinidade

\begin{tabular}{|c|c|c|c|c|}
\hline \multirow{2}{*}{$\begin{array}{l}\text { Salinidade } \\
\left(\mathrm{dS} \mathrm{m}^{-1}\right)\end{array}$} & MFPA & MSPA & PF & \multirow{2}{*}{$\begin{array}{c}D C \\
(\mathrm{~mm})\end{array}$} \\
\hline & \multicolumn{3}{|c|}{ (g planta ${ }^{-1}$ ) } & \\
\hline 7,10 & $1006,67 \mathrm{~A}$ & $184,42 \mathrm{~A}$ & $245,40 \mathrm{~A}$ & $11,06 \mathrm{~A}$ \\
\hline 8,70 & $856,67 \mathrm{~B}$ & 163,04 B & $188,33 \mathrm{~B}$ & $11,72 \mathrm{~A}$ \\
\hline 10,10 & $846,11 \mathrm{~B}$ & 144,83 B & 164,37 B & $11,78 \mathrm{~A}$ \\
\hline \multicolumn{5}{|l|}{ Fatorial vs Test. } \\
\hline Média & $903,15 b$ & $164,10 \mathrm{~b}$ & 199,37 b & $11,52 \mathrm{a}$ \\
\hline Testemunha & 1083,33 a & 197,93 a & 409,83 a & $12,00 \mathrm{a}$ \\
\hline DMS & 71,67 & 18,30 & 31,77 & 0,73 \\
\hline
\end{tabular}

Médias seguidas da mesma letra minúscula não diferem entre si na comparação do fatorial completo, pelo teste Tukey $(\mathrm{P}<0,05)$. Médias seguidas da mesma letra maiúscula não diferem entre si na comparação fatorial completo vs testemunha pelo teste Tukey $(P<0,05)$

A redução na MFPA ocorreu a partir do nível médio de salinidade da solução nutritiva $\left(8,7 \mathrm{dS} \mathrm{m}^{-1}\right)$, sendo a redução de 14,9\% comparando-se o nível médio de salinidade com o menor nível de salinidade $\left(7,1 \mathrm{dS} \mathrm{m}^{-1}\right)$ e se chegando a $15,9 \%$ ao se comparar o menor nível de salinidade com o maior $(10,1$

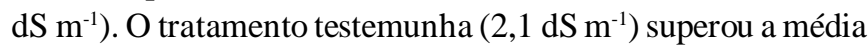
dos demais tratamentos em $16,6 \%$, o que era previsto em virtude da menor concentração de sais utilizada na testemunha.

Na Tabela 2 é mostrada a comparação entre as médias das variáveis no fatorial completo, sob diferentes níveis de salinidade, verificando-se que o aumento da concentração salina da solução nutritiva provocou redução das MFPA, MSPA e da PF ( $\mathrm{p}<0,05)$, com exceção do DC.

O comportamento da MSPA foi semelhante ao da MFPA (Tabela 2), chegando a diminuir em 21,5\% a MSPA comparandose quando da aplicação do nível de salinidade mais baixo (2,1 $\mathrm{dS} \mathrm{m}^{-1}$ ), com o mais elevado (10,1 dS m¹). Para esta variável a testemunha superou, em $17,1 \%$, a média dos demais 
tratamentos. As perdas ocorridas nessas variáveis refletem o efeito negativo do potencial osmótico da solução nutritiva, em razão do estresse salino sobre o crescimento do tomateiro em sistema hidropônico, uma vez que o estresse reduz o potencial hídrico, inibindo a absorção de água pelas plantas e a capacidade fotossintética, devido a vários fatores, tais como: desidratação das membranas celulares, toxicidade por sais, redução do suprimento de $\mathrm{CO}_{2}$ (fechamento de estômatos), senescência induzida pela salinidade e mudança na atividade das enzimas (Iyengar \& Reddy, 1996). Outros autores, como Oliveira et al. (2007) obtiveram, cultivando tomate em solo para a biomassa seca da parte aérea, redução de 48,4\% para o nível

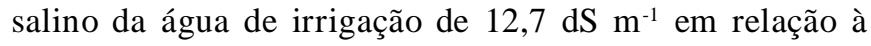
testemunha $\left(0,01 \mathrm{dS} \mathrm{m}^{-1}\right)$.

A produção dos frutos (PF) foi a variável mais afetada pela salinidade da solução nutritiva (Tabela 2) haja vista que a redução atingiu 33,0 \% entre o nível de maior salinidade $(10,1$

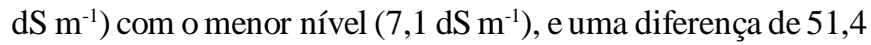
$\%$ entre a média dos tratamentos e a testemunha, evidenciando que a produção dos frutos do tomateiro é reduzido com a exposição das plantas à salinidade, ocasionando diminuição da produtividade do tomateiro. De acordo com Cuartero \& Fernández-Muñoz (1999), os frutos originados de plantas sob tratamentos salinos parecem crescer normalmente durante a fase de divisão celular, no entanto, durante a fase de expansão celular os efeitos deletérios dos sais são observados. Bolarin et al. (2001), observaram redução da produção dos frutos do tomateiro em função da salinidade, colhidos em diferentes estágios de desenvolvimento. Com referência ao diâmetro do colo (DC), não ocorreram diferenças significativas (Tabela 2).

As comparações entre as médias das variáveis no fatorial completo com a época de início da aplicação das soluções salinas (EA) são mostradas na Tabela 3; constata-se que EA afetou significativamente as variáveis MSPA e PF $(p<0,05)$, não ocorrendo influencia sobre as médias da MFPA e DC; já a comparação das médias do fatorial completo com a testemunha mostrou diferença significativa para MFPA, MSPA e PF ( $\mathrm{p}<$ 0,05), excetuando-se apenas o DC (Tabela 3).

Tabela 3. Médias das variáveis matéria fresca (MFPA) e seca (MSPA) da parte aérea, produção de frutos (PF) e diâmetro do colo (DC) do tomateiro, em função da época de início da aplicação da salinidade (EA)

\begin{tabular}{|c|c|c|c|c|}
\hline \multirow{2}{*}{$\begin{array}{c}\text { Época de início } \\
\text { da aplicação } \\
\text { da salinidade (EA) }\end{array}$} & MFPA & MSPA & PF & \multirow{2}{*}{$\begin{array}{c}D C \\
(\mathrm{~mm})\end{array}$} \\
\hline & \multicolumn{3}{|c|}{ (g planta ${ }^{-1}$ ) } & \\
\hline 7 DAT & $872,22 \mathrm{~A}$ & 153,91 B & 153,47 B & $11,39 \mathrm{~A}$ \\
\hline 32 DAT & $911,67 \mathrm{~A}$ & $166,84 A B$ & $210,60 \mathrm{~A}$ & $11,61 \mathrm{~A}$ \\
\hline 58 DAT & $925,56 \mathrm{~A}$ & $172,54 \mathrm{~A}$ & $234,02 \mathrm{~A}$ & $11,56 \mathrm{~A}$ \\
\hline \multicolumn{5}{|l|}{ Fatorial vs Test. } \\
\hline Média & $903,15 \mathrm{~b}$ & $164,43 b$ & 199,36 b & $11,52 \mathrm{a}$ \\
\hline Testemunha & 1083,33 a & 197,93 a & 409,83 a & $12,00 \mathrm{a}$ \\
\hline DMS & 71,66 & 18,30 & 31,77 & 0,73 \\
\hline
\end{tabular}

Médias seguidas da mesma letra minúscula não diferem entre si na comparação do fatorial completo, pelo teste Tukey $(P<0,05)$. Médias seguidas da mesma letra maiúscula não diferem entre si na comparação fatorial completo vs testemunha pelo teste Tukey $(P<0,05)$

Com relação a MFPA, a testemunha foi superior em 16,3\% em relação à média dos demais tratamentos (Tabela 3 ); já para MSPA, não houve diferença entre o inicio da aplicação da salinidade aos 7 e 32 DAT nem entre 32 e 58 DAT mas, comparando-se a média da EA - 7 DAT com a EA - 58 DAT, observa-se uma redução de $10,8 \%$; tal fato mostra o efeito da salinidade na planta do tomateiro, quando exposta aos sais da solução nutritiva em cultivo hidropônico por maiores períodos de tempo durante o seu desenvolvimento. Na comparação da testemunha com os demais tratamentos, esses tiveram uma redução na MSPA de 16,9\%.

Com relação a PF, a EA afetou, de forma mais acentuada, esta variável, ocorrendo uma redução de 27,1 \% comparandose a EA - 7 DAT com a EA - 32 DAT e se chegando a atingir 34,4 \% comparando-se a EA - 7 DAT com a EA - 58 DAT, não havendo diferença entre EA - 32 DAT e EA - 58 DAT.

Resposta semelhante ocorreu com Saito et al. (2006), cultivando o tomateiro em sistema hidropônico NFT, que obtiveram uma redução no produção dos frutos de $54 \%$, quando aplicaram uma solução nutritiva de condutividade elétrica de 8,0 dS m${ }^{-1}$, a partir do início da antese das flores.

O desenvolvimento vegetativo do tomateiro representado pelas MFPA, MSPA e DC, sofreu efeito significativo $(\mathrm{P}<0,05)$ do fator tratamento aplicado, com exceção do DC, que não sofreu efeito significativo $(\mathrm{P}>0,05)$ dos tratamentos aplicados (Tabela 4).

Tabela 4. M atéria fresca (M FPA) e seca (M SPA) da parte aérea, produção de frutos (PF) e diâmetro do colo (DC), médias em relação ao tratamento testemunha

\begin{tabular}{ccccc}
\hline Tratamentos & MFPA & MSPA & PF & DC \\
\cline { 2 - 4 } & \multicolumn{3}{c}{ ( $\mathbf{m}$ planta $^{-1}$ ) } \\
$\mathrm{T}_{1}\left(\mathrm{~S}_{1} \mathrm{~S}_{1} \mathrm{~S}_{1}\right)$ & $1000,00^{\text {ns }}$ & $184,40^{\text {ns }}$ & $218,60^{\#}$ & $10,83^{\text {ns }}$ \\
$\mathrm{T}_{2}\left(\mathrm{~S}_{0} \mathrm{~S}_{1} \mathrm{~S}_{1}\right)$ & $1016,66^{\text {ns }}$ & $183,93^{\text {ns }}$ & $254,56^{\#}$ & $11,16^{\text {ns }}$ \\
$\mathrm{T}_{3}\left(\mathrm{~S}_{0} \mathrm{~S}_{0} \mathrm{~S}_{1}\right)$ & $1003,33^{\text {ns }}$ & $187,93^{\text {ns }}$ & $263,03^{\#}$ & $11,17^{\text {ns }}$ \\
$\mathrm{T}_{4}\left(\mathrm{~S}_{2} \mathrm{~S}_{2} \mathrm{~S}_{2}\right)$ & $778,33^{\#}$ & $144,57^{\#}$ & $132,93^{\#}$ & $11,66^{\text {ns }}$ \\
$\mathrm{T}_{5}\left(\mathrm{~S}_{0} \mathrm{~S}_{2} \mathrm{~S}_{2}\right)$ & $876,67^{\#}$ & $162,80^{\text {ns }}$ & $196,86^{\#}$ & $11,50^{\text {ns }}$ \\
$\mathrm{T}_{6}\left(\mathrm{~S}_{0} \mathrm{~S}_{0} \mathrm{~S}_{2}\right)$ & $895,00^{\#}$ & $181,76^{\text {ns }}$ & $235,20^{\#}$ & $12,00^{\text {ns }}$ \\
$\mathrm{T}_{7}\left(\mathrm{~S}_{3} \mathrm{~S}_{3} \mathrm{~S}_{3}\right)$ & $818,33^{\#}$ & $132,77^{\#}$ & $108,90^{\#}$ & $11,66^{\text {ns }}$ \\
$\mathrm{T}_{8}\left(\mathrm{~S}_{0} \mathrm{~S}_{3} \mathrm{~S}_{3}\right)$ & $841,66^{\#}$ & $153,80^{\#}$ & $180,36^{\#}$ & $12,16^{\text {ns }}$ \\
$\mathrm{T}_{9}\left(\mathrm{~S}_{0} \mathrm{~S}_{0} \mathrm{~S}_{3}\right)$ & $878,33^{\#}$ & $147,93^{\#}$ & $203,83^{\#}$ & $11,50^{\text {ns }}$ \\
$\mathrm{Test}_{0}\left(\mathrm{~S}_{0} \mathrm{~S}_{0} \mathrm{~S}_{0}\right)$ & 1083,33 & 197,93 & 409,83 & 12,00 \\
DMS & 144,65 & 36,94 & 64,12 & 1,47 \\
\hline
\end{tabular}

(ns) não significativo $\mathrm{e}^{(\#)}$ diferença significativa em relação ao tratamento testemunha pelo teste Dunnett a 0,05 de probabilidade

Analisando as médias da variável MFPA para os tratamentos dispostos na Tabela 4, observa-se que houve uma redução em relação ao tratamento testemunha a partir do tratamento $\mathrm{T}_{4}$, quando se utilizou o nível intermediário de salinidade $\left(\mathrm{S}_{2}=8,7\right.$ $\mathrm{dS} \mathrm{m}^{-1}$ ), porém o mesmo comportamento não foi observado para MSPA, em que os tratamentos $\mathrm{T}_{5}$ e $\mathrm{T}_{6}$, (mesmo nível de salinidade do $\mathrm{T}_{4}$ ) não foram significativos, caracterizando uma influência maior da salinidade, quando aplicada no estágio inicial do desenvolvimento da planta do tomateiro.

Apesar dos tratamentos $\mathrm{T}_{1} \mathrm{~T}_{2} \mathrm{e} \mathrm{T}_{3}$, onde o nível de salinidade era o mais baixo $\left(S_{1}=7,1 \mathrm{dS} \mathrm{m} \mathrm{m}^{-1}\right)$, não apresentarem efeito significativo em relação à testemunha para MFPA e MSPA, o comportamento para o PF foi diferente; neste caso, todos os tratamentos reduziram esta variável, com quedas de produção de até $73,42 \%$ para o tratamento $\mathrm{T}_{7}$ nível mais alto de salinidade $\left(\mathrm{S}_{3}=10,1 \mathrm{dS} \mathrm{m}^{-1}\right)$, aplicado a partir do 7 DAT (Tabela 2), ou seja, 
a produtividade do tomateiro é mais reduzida quando se aplica a salinidade nos estágios iniciais do seu desenvolvimento, em concordância com Bao \& Li (2010) que obtiveram redução na produção do tomateiro de até $97,0 \%$, para o tratamento salino $\left(16,67 \mathrm{dS} \mathrm{m}^{-1}\right)$ aplicado no estágio inicial da floração.

Devido ao fato de terem sido constatados valores relativamente baixos para a produção de frutos nas condições estudadas, ressalta-se que não foi aplicada lâmina para lixiviação dos sais durante as irrigações, o que promoveu uma concentração salina muito elevada para o extrato de saturação do substrato (Figura 1) obtido ao final do experimento.

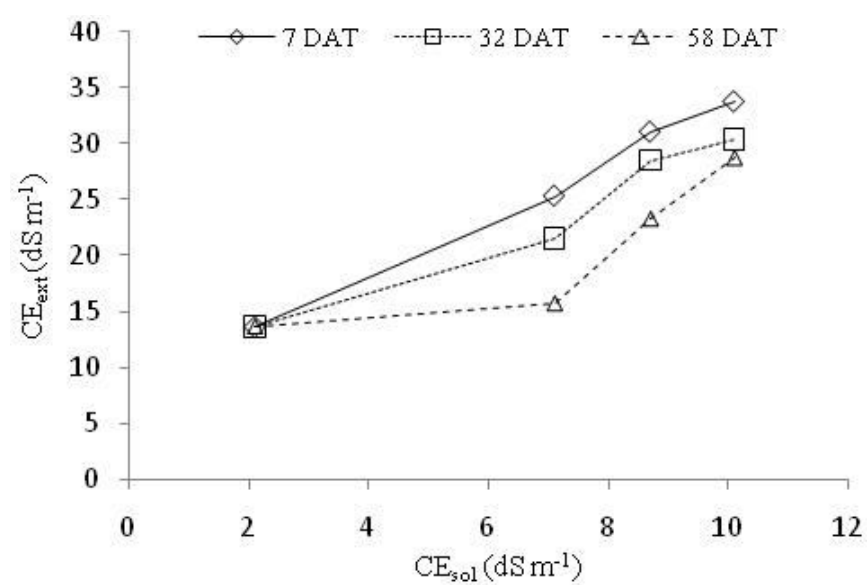

Figura 1. Concentração do estrato de saturação do substrato ao final do ciclo de cultivo em função da salinidade da solução nutritiva, nas diferentes épocas de início de aplicação

Os valores das concentrações do extrato de saturação do substrato variaram de 13,6 a $33,7 \mathrm{dS} \mathrm{m}^{-1}$ (Figura 1). As referidas concentrações estão acima de $13 \mathrm{dS} \mathrm{m}^{-1} 1\left(\mathrm{CE}_{\mathrm{es}}\right)$ que, segundo Ayers \& Westcot (1999), seria a nível de salinidade do solo na qual o tomateiro teria produção relativa zero. Percebe-se daí, a importância do uso do sistema hidropônico com substrato de fibra de coco quando se tem águas de salinidade elevada para utilizar na solução nutritiva, a exemplo da água de rejeito salino.

Esta alta concentração de sais é um fator de estresse para as plantas, sendo a água osmoticamente retida em uma solução salina; para Taiz \& Zeiger (2006), o aumento da pressão osmótica do substrato atua de forma negativa sobre o processo fisiológico, reduzindo a absorção de água pelas raízes, inibindo a atividade meristemática, o alongamento celular e, como consequência, a redução no crescimento e desenvolvimento das plantas.

\section{CONCLUSÕES}

1. A salinidade da solução nutritiva, produzida pelo rejeito salino, reduziu de forma significativa a massa fresca da parte aérea, massa seca da parte aérea e a produção dos frutos da cultura do tomate.

2. A época de início da aplicação da salinidade às plantas de tomateiro reduziu, de forma significativa, a matéria seca da parte aérea e a produção de frutos, quando aplicada a partir dos 7 DAT.
3. A interação da salinidade do rejeito com sua época de início de aplicação na solução nutritiva às plantas de tomateiro, não produziu efeito significativo para as variáveis do tomateiro estudadas.

\section{LITERATURA CITADA}

Agrianual 2008. FNP. Consultoria e comércio. Anuário da agricultura brasileira. São Paulo, 2008. 502p.

Ayers, R.S.; Westcot, D.W. A qualidade da água na agricultura. 2.ed. Campina Grande: UFPB, 1999. 153p. Estudos FAO Irrigação e Drenagem, 29.

Bao, H.; Li, Y. Effect of stage-specific saline irrigation on greenhouse tomato production. Irrigation Science, v.28, p.421-430, 2010.

Bolarin, M. C.; Estañ, M. T.; Caro, M.; Romero-Aranda, R.; Cuartero, J. Relationship between tomato fruit growth and fruit osmotic potential under salinity. Plant Science, v.160, p.1153-1159, 2001.

Carmo Filho, F. do; Oliveira, O. F. Mossoró: Um município do semiárido nordestino, caracterização climática e aspecto florístico. Mossoró: ESAM, 1995. 62p. Coleção Mossoroense, Série B

Costa, A. M. B.; Melo, J. G.; Silva, F. M. Aspectos da salinização das águas do aquí́fero cristalino no estado do Rio Grande do Norte, Nordeste do Brasil. Águas Subterrâneas, v.20, p.67-82, 2006.

Cuartero J.; Fernandez-Munõz, R. Tomato and salinity. Scientia Horticulturae, v.78, p. 83-125, 1999.

Dias, N. S.; Lira, R. B.; Brito, B. L.; Sousa Neto, O. N.; Ferreira Neto, M.; Oliveira, A. M. Produção de melão rendilhado em sistema hidropônico com rejeito da dessalinização de água em solução nutritiva. Revista Brasileira de Engenharia Agrícola eAmbiental, v.14, p.755-761. 2010.

Furlani, P. R.; Silveira, L. C. P.; Bolonhezi, D.; Faquim, V. Cultivo hidropônico de plantas. Campinas: Instituto Agronômico, 1999. 52p. Boletim Técnico, n.180

Iyengar, E.R.R.; Reddy, M.P. Photosynthesis in highly salt tolerant plants. In: Pessarakli, M. (ed.) Handbook of photosynthesis. Baten Rose: Marshal Dekar. 1996. P.897909.

Maas, E. V. Crop salt tolerance. In: Tanji, K. K. (ed.) Agricultural salinity assessment and management manual. New York: ASCE, 1990. p.262-304.

MME - Ministério de Minas e Energia. Projeto cadastro de fontes de abastecimento por água subterrânea. Diagnóstico do município de Mossoró, estado do Rio Grande do Norte. Recife: CPRM/PRODEEM, 2005. 11p.

Oliveira, B. C.; Cardoso, M. A. A.; Oliveira, J. C.; Oliveira, F. A.; Cavalcanti, L. F. Características produtivas do tomateiro submetida a diferentes níveis de sais, na água de irrigação. Revista Brasileira de Engenharia Agrícola e Ambiental, v.11, p.11-16, 2007.

Porto, E. R.; Amorim, M. C. C. de; Araújo, O. J. Potencialidades da erva-sal (Atriplex nummularia) irrigada com o rejeito da dessalinização de água salobra no semi-árido brasileiro como alternativa de reutilização. http://www.cepis.ops-oms.org/ bvsaidis/ aresidua/X-003.pdf. $10 \mathrm{Jul} .2004$. 
Saito, T.; Fukuda, N.; Nishimura, S. Effects of salinity treatment duration and planting density on size and sugar content oh hydroponically grow tomato fruits. Japanese Society for Horticultural Science, v.75, p.392-398, 2006.

Santos, A. N.; Soares, T. M.; Silva, E. F. F.; Silva, D. J. R.; Montenegro, A. A. A. Cultivo hidropônico de alface com água salobra subterrânea e rejeito da dessalinização em Ibimirim, PE. Revista Brasileira de Engenharia Agrícola e Ambiental, v.14, p.961-969, 2010a.

Santos, R. S. S.; Dias, N. S.; Sousa Neto, O. N.; Gurgel, M. T. Uso do rejeito da dessalinização de água salobra no cultivo da alface (Lactuca sativa 1.) em sistema hidropônico NFT. Ciência e Agrotecnologia, v.34, p.983-989, 2010 b.
Soares, T. M.; Silva, I. J. O.; Duarte, S. N.; Silva, E. F. F. Destinação de águas residuárias provenientes do processo de dessalinização por osmose reversa. Revista Brasileira de Engenharia Agrícola e Ambiental, v.10, p.730737, 2006.

Soares, T. M.; Silva, E. F. de F. e; Duarte, S. N.; Mélo, R. F.; Jorge, C. A; Bonfim-Silva, E. M. Produção de alface utilizando águas salinas em sistema hidropônico. Irriga, v.12, p.235-248, 2007.

Taiz, L.; Zeiger, E. Fisiologia vegetal. 3.ed. Porto Alegre: Artmed, 2006. 719p.

Teixeira, N. T. Hidroponia: Uma alternativa para pequenas áreas. Guaíba: Agropecuária. 1996. 86p. 